\title{
Electrochemical
}

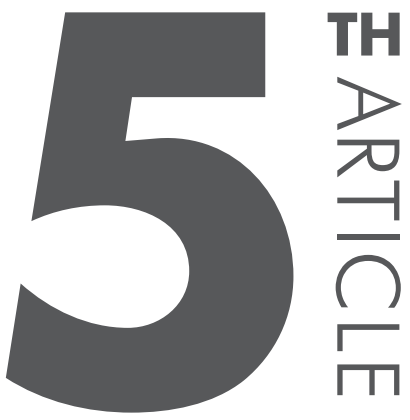

\section{coloration of stainless \\ steel as an alternative for architectural coatings}

Rosa Maria Rabelo Junqueira', Célia Regina de Oliveira Loureiro

Instituto Senai de Inovação de Engenharia de Superfícies - Centro de Tecnologia Senai Cetec - DR MG Av. José Cândido da Silveira, 2000, 31035-536 - Belo Horizonte/MG - Brasil

${ }^{1}$ corresponding author

\section{ABSTRACT}

The characterization of architectural coatings grown on the surface of AISI 304 stainless steel by an electrochemical coloration process was realized by multiple techniques. The interference colored coatings were grown in a sulphochromic solution at room temperature by an alternating pulse current method. The morphology and chemical state of the elements in the films were investigated by field emission scanning electron microscopy (FESEM), atomic force microscopy (AFM), glow discharge optical emission spectrometry (GDOES), and infrared Fourier transform spectroscopy (FTIR). Depth-sensing indentation (DSI) experiments and wear abrasion tests were employed to assess the mechanical resistance of the films. The coloration process resulted in porous thin films which increased the surface roughness of the substrate. The interference films mainly consisted of hydrated chromium oxide containing iron. Increasing film thickness produced different colors and affected the mechanical properties of the coating-substrate. 


\section{INTRODUCTION}

The deposition of interference thin films on the surface of stainless steel is an important method for enhancing the decorative and architectural application of this material. A wide variety of interference colors, including brown, blue, gold, purple, and green, can be obtained, in this exact sequence, as the film thickness is increased from tenths of nanometers to approximately one half of a micrometer [1]. Further, this thin passivation layer on stainless steel improves its surface properties [2], increasing the number of potential applications. The INCO (International Nickel Limited) process was the first method developed for fabricating interference coloring on stainless steel, where the steel

is chemically treated in a hot solution of sulphuric acid containing chromate ions $[3,4]$. Electrochemical methods using square wave potential pulse polarization in hot sulphuric acid solutions were later developed [5]. A similar method using sulphochromic solutions at room temperature has also been developed for growing these interference oxide films on the surface of stainless steel $[6,7]$.

The performance and reliability of these interference films are limited by their resistance to the scrubbing action of routine cleaning operations. Unfortunately, the testing of architectural coatings is often the function of a complex interaction of various coating physical characteristics. The characterization of film structure, composition, and

morphology is the first step towards understanding the reactions taking place during the deposition, and can be used to control film properties and develop new products and processes. It has been already demonstrated that the mechanical resistance of interference films is affected by the deposition process [8]. In addition, the morphology of electrochemically deposited interference films has been associated with their mechanical resistance. In a previous work, in which film porosity was varied by employing different deposition conditions, an inverse linear correlation was found between hardness and film porosity [9].

Considering that this kind of film is made up of very small struc $\neg$ tures, high resolution techniques, such as field emission scanning electron microscopy (FESEM) and atomic force microscopy (AFM), are needed to analyze their morphology. Therefore, such studies are scarcely found in the literature. The thickness and in-depth com $\neg$ position of these films have been investigated using Auger electron spectroscopy (AES) and secondary ion mass spectrometry (SIMS) [10,11]. These studies showed that electrochemically deposited interference films on stainless steel surfaces are mainly constituted of chromium oxide. Other studies using X ray photoelectron spectroscopy (XPS) have confirmed the presence of chromium in the form of $\mathrm{Cr}(\mathrm{III})$ and have indicated the presence of $\mathrm{Fe}$ and $\mathrm{Ni}$ within the interference film $[12,13]$. 
The present study intends to contribute to the understanding of the nature of interference films grown by alternating pulse current on austenitic stainless steel. The morphology and the chemical state of the elements in the films were investigated by FESEM, AFM, GDOES (glow discharge optical emission spectrometry) and FTIR (infrared Fourier transform spectroscopy). Depth-sensing indentation (DSI) experiments and wear abrasion tests were employed to assess the mechanical resistance of the films.

\section{EXPERIMENTAL METHODS}

\subsection{Sample preparation}

Specimens of $200 \times 200 \times 0.8 \mathrm{~mm}$ were cut from a sheet of bright buffing (BB) type AISI 304 stainless steel, degreased in ethanol, and rinsed in distilled water before immersion in an aqueous solution containing $2.5 \mathrm{M} \mathrm{CrO}_{3}$ and $5.0 \mathrm{M}$ $\mathrm{H}_{2} \mathrm{SO}_{4}$, for coloration by means of the alternating pulse current method, at room temperature, as pre $\neg$ viously described elsewhere [9].

\subsection{Reflectance spectrometry analysis}

The color tones of the samples were controlled by the chroma coordinates: L (brightness), C (chroma), and h (hue), characteristic of brown, blue, gold, and green colors. These coordinates were measured in a reflectance spectrophotometer using a D65 light source and a $10^{\circ}$ standard observer. The measurement of reflectance was conducted in a ColorQuest II - HunterLab reflectance spectrophotometer, for wavelengths in the range of 400 to $700 \mathrm{~nm}$.

\subsection{Morphological analysis}

FESEM images were acquired in a Hitachi ${ }^{\circledR} S 5000$ at $2.0 \mathrm{kV}$ and 100,000 to 300,000 magnifications for each sample in order to characterize the morphology of the interference films. The film roughness was evaluated from AFM images acquired in a Digital Dimension 3000 equipment, operating in intermittent contact mode using a silicon nitride tip. The scan size was $2 \times 2 \mu \mathrm{m}$. The roughness, expressed as the root mean square $(\mathrm{Rq})$ parameter, was obtained after having processed nine AFM images for each sample.

\subsection{GDOES analysis}

The depth-concentration profiles of the coatings were obtained by GDOES analysis using a Shimadzu GDLS 9950 RF instrument. Specimens colored in brown, blue, gold, and green were sputtered in a high purity $(99.999 \%)$ argon atmosphere of $25 \mathrm{~Pa}$ by apply 7 ing a radio frequency of $13.56 \mathrm{MHz}$ at a power 
of $20 \mathrm{~W}$. The inner diameter of the anode was $4 \mathrm{~mm}$. Three samples of each of the four colors were employed and three measurements were performed in one sample, totaling nine measurements for each color. The tests were conducted in sequence on the same day to avoid the oscillations inherent to the technique.

\subsection{FTIR analysis}

The chemical bonding of the films were characterized by FTIR reflection spectra in the spectral range from 4000 to $500 \mathrm{~cm}-1$, obtained in the stainless steel substrate and in gold colored samples using a Nicolet Nexus 470 spectrometer.

\subsection{Depth-sensing indentation experiments}

DSI experiments were performed in a Shimadzu DUHW201S instrumented indentation tester with a load range of 0.1 to $1960 \mathrm{mN}$, a maximum penetration depth of $10 \mu \mathrm{m}$ and an indenter shift resolution of $1 \mathrm{~nm}$. A Berkovich triangular pyramid with $115^{\circ}$ tip angle was used as an indenter. A load of $5 \mathrm{mN}$ was applied at a rate of $0.178 \mathrm{mN} / \mathrm{s}$. The holding time was 5 seconds, and load-displacement curves were registered in all experiments. The DSI measurements were carried out on the stainless steel substrate as well as on specimens colored in brown, blue, gold, and green. A minimum of five experiments were performed per load. From the load-displacement data, the values of elastic modulus and hardness of the interference films were calculated using the Oliver \& Pharr approach [14].

\subsection{Dry abrasion resistance}

Dry abrasion resistance experiments were performed on a SUGA NUS-ISO3 abrasion tester machine for coated materials. The specimens were submitted to a sliding movement back and forth on a horizontal plane under a load of $30 \mathrm{~N}$, and their surface was abraded by reciprocal motion against a strip of a $0.5 \mu \mathrm{m}$ $\mathrm{CrO}_{3}$ abrasive paper attached do the outer circumference of a turning wheel. Nine experi $\neg$ ments were performed for each color, and the mean number of strokes necessary to expose the substrate was recorded as the wear abrasion resistance of the coating.

\subsection{Statistical analysis}

Analysis of variance for completely randomized design [15] and Duncan post hoc test at an alpha level of 0.05 were adopted to compare the results of roughness and thickness measurements as well as the mechanical properties of the different coatings [16]. 


\section{RESULTS AND DISCUSSION}

\subsection{Morphology}

The surface morphology of the interference film is illustrated in Figure 1 by means of a typical FESEM image for a gold colored sample, in which pores and discontinuities can be observed. The to $\neg$ pography of the film is shown in the AFM images of the same sample and of the steel substrate presented in Figure 2. The AFM tridimensional images show the smoother surface of the substrate when compared to the surface of the film. This evidence was reinforced by the mean roughness $(\mathrm{Rq})$ values of $3.6 \pm 0.7 \mathrm{~nm}$ and $4.9 \pm 0.8 \mathrm{~nm}$ obtained for the uncovered substrate and the colored sample, respectively. A significant difference was found between these values, indicating that the film has a higher roughness than the substrate.

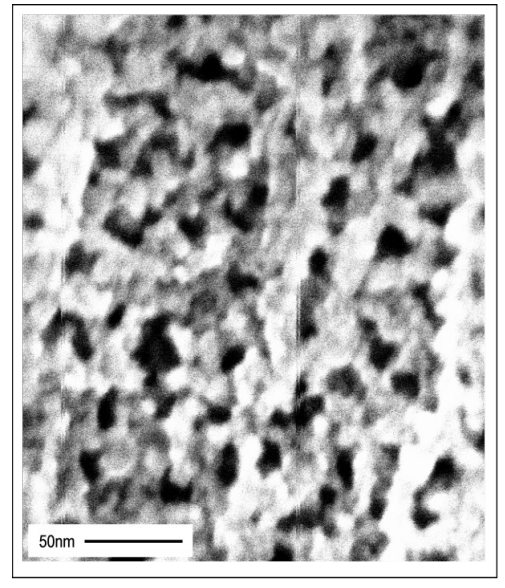

Figure 1 - Typical FESEM image of a gold colored interference film

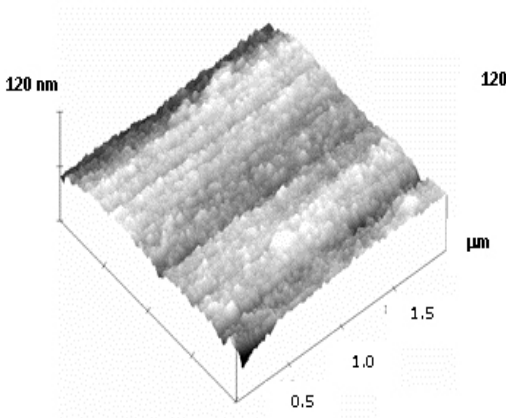

(a)

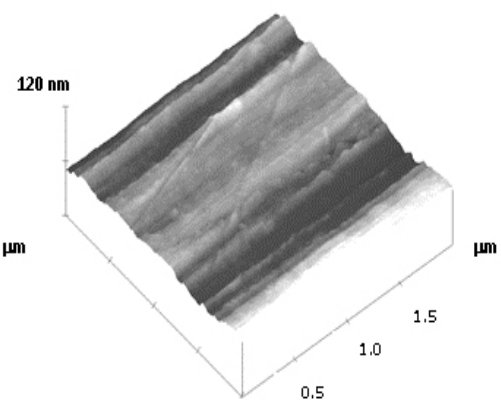

(b)

Figure 2 - AFM images of a gold colored sample (a) and the uncovered substrate (b) 


\subsection{Film thickness}

Typical GDOES depth profiles for Fe, O, Cr, and Ni in the brown, blue, gold, and green samples are shown in Figure 3. For all four colors, a sharp decrease in oxygen and an increase in iron were observed until a steady and constant intensity was reached, thus allowing for the location of a metal/film interface at the intersec $\neg$ tion point of the oxygen and iron lines [17].
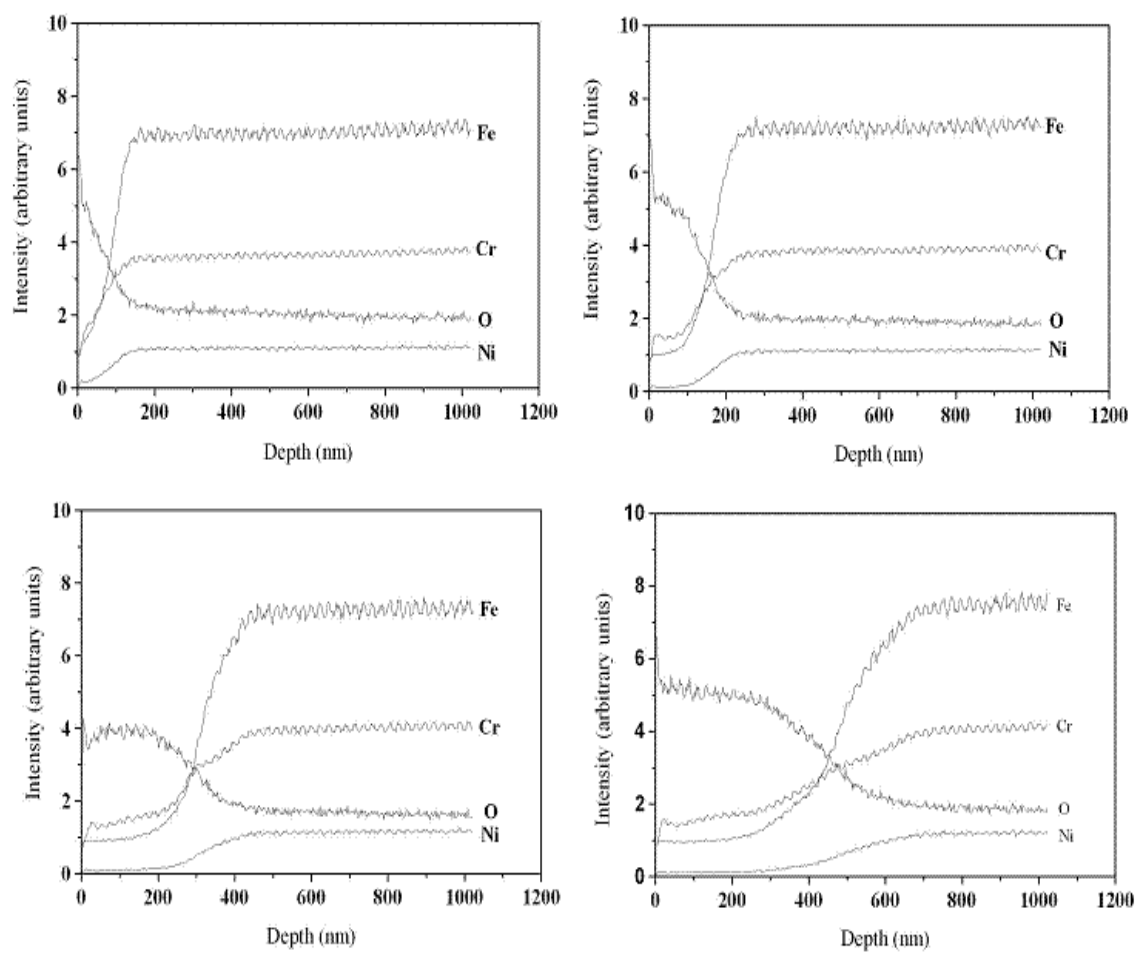

Figure 3 - GDOES depth profiles of interference films colored in (a) brown (b)blue, (c) gold and (d) green

The mean values of film thickness estimated from GDOES depth profiles are shown in Figure 4. A significant increase in film thickness from $\sim 70 \mathrm{~nm}$ (brown) to $\sim 40 \mathrm{~nm}$ (green) was found in the samples. Similar results were obtained by Evans1 for interference films grown on stainless steel by a chemical process. Using reflect $\neg$ ance spectrophotometry, Evans1 estimated a $400 \mathrm{~nm}$ thickness for the interference film of the green sample. Lin \& Duh [18] calculated the thickness of interference films grown by pulsed current and chemical methods through the depth profiling of these films using SIMS and found values similar to those shown in Figure 4. They also reported that there was no significant difference in thickness between films made by the pulsed current method and those made by the INCO chemical method. 


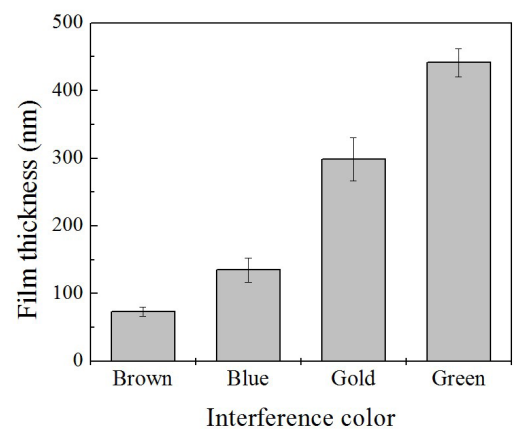

Figure 4 - Thickness (nm) of interference colored film measured by GDOES technique

\subsection{Chemical bonding}

FTIR spectra of the steel substrate and of a gold colored sample are presented in Figure 5. In contrast with the steel substrate, for the colored sample there is a large absorption band centered at $3382 \mathrm{~cm}^{-1}$ corresponding to $\mathrm{O}-\mathrm{H}$ bonding, which can be attributed to water of hydration incorporated within the surface oxide layer. The sharper band at $561 \mathrm{~cm}-1$ is due to a Cr-O stretching mode arising from the chromium oxide coating [19], whereas the less intense band centered at $1136 \mathrm{~cm}^{-1}$ is similar to Fe-O-H bending vibrations in goethite [20]. Smaller-intensity bands were not sufficiently resolved to be helpful in this analysis and can be assigned to contamination from the environ $\neg$ ment. In the infra-red analysis of interference colored stainless steel carried out by Evans et al. [3] a strong absorption band on $3370 \mathrm{~cm}^{-1}$, which was attributed to coordination water, and another band in the metal-oxide region revealing the presence of chromium oxide, were detected. In a similar work using TEM/EDS and XPS, Fujimoto et al. [12] found that the interference film consisted of a $\mathrm{Cr}_{2} \mathrm{FeO}_{4}$ spinel oxide with excess $\mathrm{Cr}$. Thus, the FTIR spectra obtained in the present work indicated that the interference films grown on stainless steel surfaces by means of the electrochemical method are mainly composed of hydrated chromium oxide containing iron.

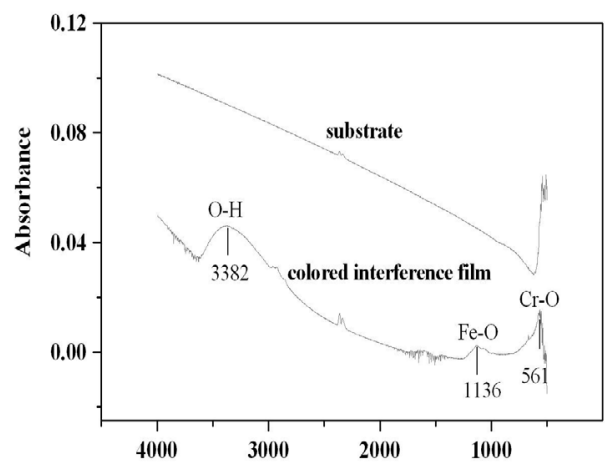

Figure 5 - FTIR spectra of a gold colored interference film grown on AISI 304 stainless steel 


\subsection{Mechanical properties}

Typical load-displacement curves obtained with a $5 \mathrm{mN}$ load are shown in Figure 6 for the colored samples and the steel substrate. The unloading section of the curves for the colored samples was displaced to the right, indicating a lower hardness when compared with the substrate9. According to Page and Hainsworth [21], this behavior is typical of soft films on hard substrates. As the interference film thickness is increased from $\sim 70 \mathrm{~nm}$ (brown) to $\sim 440 \mathrm{~nm}$ (green), the displacement of the unload curve to the right is more accentuated. This observation indicates that the influence of the substrate on me-chanical properties of the composite is stronger for the thinner films with brown and blue interference colors than for the thicker films colored in gold and green. On the other hand, the proximity of the load-displacement curves for the thicker films (curves $\mathrm{C}$ and D) in Figure 6 are due to the slight hardness difference between the green and gold films, reflecting a tendency towards the stabilization of the influence of film thickness on this property.

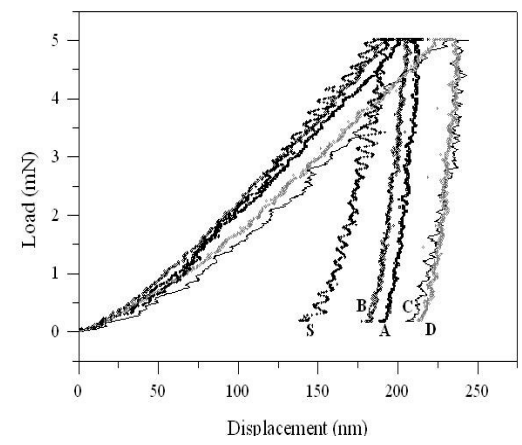

Figure 6 - Load-displacement curves of AISI 304 stainless steel substrate (S) and colored stainless steel in brown (A), blue (B), gold (C) and green (D)

The values of indentation hardness $(\mathrm{H})$ and elastic modulus $(\mathrm{E})$ were calculated using the Oliver \& Pharr approach [14] and plotted against film thickness in Figure 7. The data points represent the mean of five measurements, with standard deviations smaller than $10 \%$ of the mean values. The film thickness for the uncoated substrate was taken as zero, for simplicity. The total elastic-plastic deformation, $\mathrm{W}_{\text {tot, }}$ calculated as the area underneath the load-displacement curves, is also plotted in Figure 7a, while the ratio H/E, called the plasticity index [22], is plotted in Figure 7b. These results indicated that the film hardness decreased and $\mathrm{W}_{\text {tot }}$ increased as the coating thickness increased. There was also a tendency for the elastic modulus to decrease, causing an increase in the plasticity index as the film thickness increased. This behavior once again emphasizes that the substrate is harder than the interference films. The higher mechanical resistance of the substrate has been already observed in nanoscratching experiments performed on a gold colored stainless steel sample as compared to the uncoated substrate [9]. 


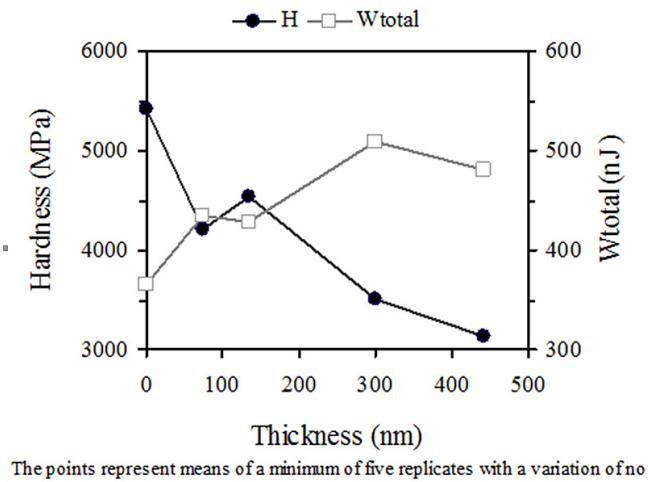

The points represent means of a minimum of five replicates with a variation of no more than $10 \%$.

(a)

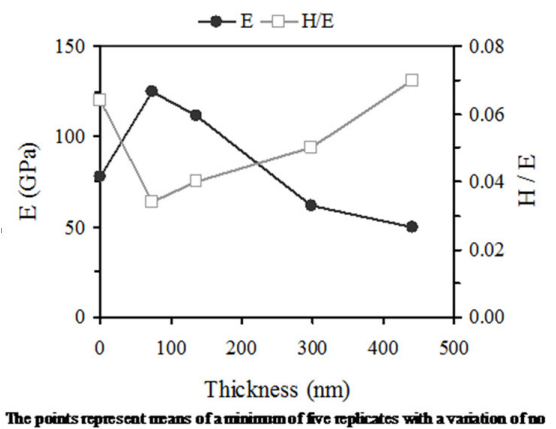

more than $10 \%$

(b)

Figure 7 - Mechanical parameters obtained in depth sensing indentation experiments as a function of interference film thickness. (a) indentation hardness ( $\mathrm{H}$ ) and total elastic-plastic deformation Wtotal ( $\mathrm{nJ}$ )

(b) Elastic modulus (E) and $\mathrm{H} / \mathrm{E}$ (plasticity index)

\subsection{Wear abrasion resistance}

The wear abrasion resistance of the interference films, expressed as the mean number of strokes in nine experiments (deviation less than $10 \%$ ), is plotted against film thickness in Figure 8. The H/E ratio calculated from the results of the depth-sensing experiments is also shown in this figure. It can be observed that the abrasion resistance increased as the thickness of the film increased and that the $\mathrm{H} / \mathrm{E}$ ratio showed the same tendency. According to Leyland and Matttews [22], a high plasticity index is often a reliable indicator of good wear resist 7 ance on a coating. They also comment that it is helpful for the film to have an elastic modulus which is slightly lower than the substrate. In this manner, the ranking of materials as regards their $\mathrm{H} / \mathrm{E}$ ratio can produce extremely close approximations to their ranking in terms of wear resistance. In the present work, the higher plasticity index found for the thicker gold and green films can explain their higher abrasion 
resistance in comparison with other colored samples with lower film thickness, such as those with brown and blue colors.

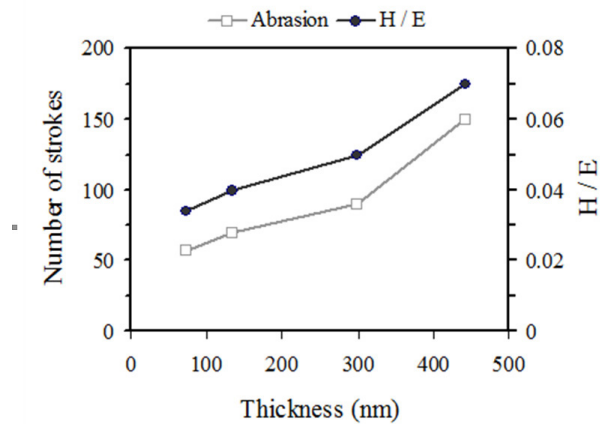

The points represent means of a minimum of nine replicates with a variation of no more than $10 \%$.

Figure 8 - Dry abrasion resistance as a function of interference film thickness and the plasticity index (H/E)

\section{CONCLUSIONS}

Characterization studies using several high resolution techniques, such as FESEM, AFM, and depth-sensing indentation were per $\neg$ formed on interference films grown on an AISI 304 stainless steel. The main conclusions can be summarized as follows: the coloration of stainless steel by a pulse current method resulted in the growth of a porous thin film on the steel surface, which in turn increased its surface roughness. These interference films mainly consisted of hydrated chromium oxide containing iron. Increasing film thickness produced different colors and affected the mechanical properties of the coating-substrate system. Consequently, thicker films, such as those producing the gold and green colors, proved to be softer but more abrasion resistant.

\section{ACKNOWLEDGEMENTS}

The authors acknowledge the financial support from Fundação de Amparo à Pesquisa do Estado de Minas Gerais.

\section{REFERENCES}

[1] Evans TE. Corrosion Science 17 (1977) 105.

[2] Conrrado R, Bocchi N, Rocha-Filho RC, Biaggio SR. Electrochimica Acta 48 (2003) 2417.

[3] Evans TE, Hart AC, Skedgell AN. Transactions of the Institute of Metal Finishing 51 (1973) 108. 
[4] Blower R, Evans TE. 51 (1974) 230.

[5] Fujimoto S, Shibata T, Wada K, Tsutae T. Corrosion Science 35 (1993) 147.

[6] Ogura K, Sakurai K, Uehara S. Journal of Electrochemical Society 141 (1994) 648.

[7] Ogura K, Lou W, Nakayama M. Electrochimica Acta 41(18) (1996) 2849.

[8] Lin C.J, Duh J.G. Thin Solid Films 287 (1996) 80.

[9] Junqueira R.M.R, Andrade M.S, Loureiro C.R.O, Buono V.T.L. Surface and Coatings Technology 201(2006) 2431.

[10] Ansell R.O, Dickinson T, Povey AF. Corrosion Science 18 (1978) 245.

[11] Sone Y, Tochihara M, Yoshioka K. Proceedings of International Conference on Stainless Steels (1991) Jun 10-13; Chiba, Japan 1006.

[12] Fujimoto S, Tsujino K, Shibata T. Electrochimica Acta (47) 2001543.

[13] Kikuti E, Bocchi N, Pastol JL, Ferreira MG, Montemor MF, Cunha Belo M, Simões AM. Corrosion Science 49 (2007) 2303.

[14] Oliver WC, Pharr GM. Journal of Materials Research 7 (1992) 1564.

[15] Montgomery DC. Design and Analysis of Experiments. 3rd ed. New York: John Wiley; 1991.

[16] Duncan DB. Biometrics 11 (1955) 1.

[17] Kerber SJ, Tverberg J. Advanced Materials and Processes 158 (2000) 33.

[18] Lin CJ, Duh, JG. Elemental redistribution in colored film on SUS304 stainless steel produced by current pulse method. Surface and Coatings Technology 1996; 85: 175-182.

[19] Lenglet M, Guillamet R, Lopitaux J, Hannoyer B. Materials Research Bulletin 25 (1990) 575.

[20] Musi S, Goti M. Mössbauer. Journal of Molecular Structrure 834-836 (2007) 445.

[21] Page TF, Hainsworth SV. Surface and Coatings Technology 61 (1993) 201.

[22] Leyland A, Matthews A. Wear 246 ( 2000) 1. 
